\title{
Human parvovirus, fifth disease, and marrow aplasia
}

Interesting and important discoveries continue to be made in the field of infectious diseases and this story is about a particularly mixed bag of laboratory and clinical observations.

During and after the 1950s virologists realised that the best way to classify viruses was to arrange them on the basis of their size, whether they had a lipid envelope or not, and what type of nucleic acid they used as a gene (and how they replicated it). On this basis a group of small viruses containing a small piece of single stranded DNA was defined and christened the parvoviruses. Only a few were known at that time; they infected animals, were very difficult to grow, and seemingly could multiply well only in dividing cells. ${ }^{1}$ Since then more have been discovered causing disease in cats and other felines (panleukopenia virus), in sealions, and recently in dogs. Some viruses can grow only in cells that are infected with other viruses and form a subgroup called 'dependoviruses'.

While checking normal human blood for hepatitis B virus, particles were detected that looked like parvoviruses and that formed a precipitate in gel quite distinct from that of hepatitis B virus. ${ }^{2}$ They were identified only by electron microscopy and thus could not be characterised exactly. They could not be grown in the laboratory, for example in tissue culture, therefore further basic studies were impossible at that time. Work went on very slowly, mainly because the only reagents were virus and antibody found in human blood. New and more sensitive techniques have been developed recently, however, using radioimmunoassay for instance rather than immune electron microscopy or immunodiffusion methods. In spite of these advances the viruses, often named after the specimen B19, remained 'orphans'-viruses in search of a disease. In the last decade parvovirus-like particles have been found in human faeces but they do not seem to be associated with disease.

Two key observations have been made recently which show that these viruses are not just the accidental, silent invaders they seemed to be. Firstly, a child in Britain who had sickle cell disease suffered an episode of marrow aplasia accompanied by serological evidence of infection with a virus related to B19. Follow up studies showed that a substantial proportion of children in the United Kingdom and Jamaica also had the same association, but because the sera were collected at long intervals it was often not possible to say whether infection took place at the same time as the haematological changes. ${ }^{3}{ }^{4}$ It seemed, however, that many of them had had a mild upper respiratory infection a week or so before the acute episode of anaemia but were not otherwise suffering from an obvious infectious disease. Since then it has been found that temporary marrow aplasia complicating other chronic anaemias may be associated with infection by the same parvovirus. ${ }^{56}$ It is possible that the virus grows in dividing marrow cells, but this is not as yet supported by any experimental results.

The second observation was made recently in North London where the Public Health Laboratories and Communicable Diseases Surveillance Centre at Colindale were asked to investigate an outbreak in which young children in a number of schools and their preschool siblings had a mild disease with a rash, which might in some cases have been allergic or in others rubella. In the end it was recognised as 'fifth disease' or erythema infectiosum. This is a condition characterised by epidemics of erythema of the face extending to the trunk and limbs, described as looking like a slapped cheek and a lace like pattern on the limbs. The rash usually varies in intensity, being particularly obvious after a bath. All the cases studied had serological evidence of infection with the same parvovirus. ${ }^{7}$ Any virus that causes viraemia may produce a rash but we know nothing of the pathogenetic mechanism in this case.

Thus, we are now poised to take off in a number of interesting directions. In the first place we can follow up these clues and find out how often these parvoviruses cause disease and what the full clinical picture is. Some of the patients with rash had arthralgia during convalescence and there are also occasional reports of hepatitis, though the latter could be a chance association. We need to know whether the organism causes other febrile disease or rashes and possibly other more serious conditions. We still do not know how the virus is shed and, although there is some evidence of respiratory symptoms, whether its dispersal is airborne is unknown. A high proportion of the population has antibodies but how many have had clinical disease?

Although the virus still cannot be grown in the usual laboratory culture systems, it may be possible to propagate it in cultured bone marrow cells and the new 'genetic engineering' techniques will also be 
a big help in overcoming this difficulty. It was recently shown that the DNA is packaged with a positive strand in some particles and a negative strand in others ${ }^{8}$ and this nucleic acid can be cloned into a plasmid, propagated in bacteria, and that radiolabelled copies, which can be used as specific, simple, and sensitive probes for the virus, can be produced, obviating the need for cultural techniques to detect small amounts of virus in clinical specimens. We can expect more interesting facts to emerge in the next few years.

\section{References}

1 Andrewes CH, Perera HG, Wildy P. Viruses of vertebrates London: Baillière Tindall, 1978:255-71.

2 Cossart Y, Cant B, Field AM, Widdows P. 'Parvovirus-like' particles in human sera. Lancet 1979;i:72-3.

3 Pattison JR, Jones SE, Hodgson $\mathrm{J}$ et al. Parvovirus infections and hypoplastic crises in sickle cell anaemia. Lancet 1981;i: 664-5.
${ }^{4}$ Sergeant GR, Topley JM, Mason K, et al. Outbreak of aplastic crisis in sickle cell anaemia associated with parvovirus-like agent. Lancet $1981 ;$ ii: 595-8.

5 Duncan JR, Potter CG, Cappellini MD, et al. Aplastic crisis due to parvovirus infection in pyruvate kinase deficiency. Lancet 1983;ii:14-6.

6 Rao KRP, Patel AR, Anderson MJ, Hodgson J, Jones SF, Pattison JR. Infection with parvovirus-like agent and aplastic crisis in adults with chronic haemolytic anaemia. Ann Intern Med 1983;98:930-2.

7 Anderson MJ, Jones SE, Fisher-Hock SP, et al. Human parvovirus, the cause of erythema infectiosum (fifth disease)? Lancet 1983;i:1378.

' Summers J, Jones SE, Anderson MJ. Characterization of the genome of the agent of erythrocyte aplasia permits its classification as a human parvovirus. J Gen Virol 1983;64:2527-32.

D A J TYRRELL MRC Common Cold Unit, Harvard Hospital, Coombe Road, Salisbury SP2 8BW 